\title{
Validation of radio-frequency dielectric heating system for destruction of Cronobacter sakazakii and Salmonella species in nonfat dry milk
}

\author{
M. Michael, ${ }^{*}$ R. K. Phebus, ${ }^{*}$ H. Thippareddi, $†$ J. Subbiah, $\ddagger$ S. L. Birla,‡ and K. A. Schmidt ${ }^{* 1}$ \\ *Food Science Institute, Kansas State University, Manhattan 66506 \\ †Department of Food Science and Technology, and \\ ‡Department of Biological Systems Engineering, University of Nebraska, Lincoln 68583
}

\section{ABSTRACT}

Cronobacter sakazakii and Salmonella species have been associated with human illnesses from consumption of contaminated nonfat dry milk (NDM), a key ingredient in powdered infant formula and many other foods. Cronobacter sakazakii and Salmonella spp. can survive the spray-drying process if milk is contaminated after pasteurization, and the dried product can be contaminated from environmental sources. Compared with conventional heating, radio-frequency dielectric heating (RFDH) is a faster and more uniform process for heating low-moisture foods. The objective of this study was to design an RFDH process to achieve target destruction (log reductions) of C. sakazakii and Salmonella spp. The thermal destruction (decimal reduction time; D-value) of C. sakazakii and Salmonella spp. in NDM (high-heat, $\mathrm{HH}$; and low-heat, $\mathrm{LH}$ ) was determined at $75,80,85$, or $90^{\circ} \mathrm{C}$ using a thermal-death-time (TDT) disk method, and the z-values (the temperature increase required to obtain a decimal reduction of the $\mathrm{D}$-value) were calculated. Time and temperature requirements to achieve specific destruction of the pathogens were calculated from the thermal destruction parameters, and the efficacy of the RFDH process was validated by heating NDM using RFDH to achieve the target temperatures and holding the product in a convection oven for the required period. Linear regression was used to determine the $\mathrm{D}$-values and $z$-values. The $\mathrm{D}$-values of C. sakazakii in HH- and LH-NDM were 24.86 and $23.0 \mathrm{~min}$ at $75^{\circ} \mathrm{C}, 13.75$ and $7.52 \mathrm{~min}$ at $80^{\circ} \mathrm{C}, 8.0$ and $6.03 \mathrm{~min}$ at $85^{\circ} \mathrm{C}$, and 5.57 and $5.37 \mathrm{~min}$ at $90^{\circ} \mathrm{C}$, respectively. The D-values of Salmonella spp. in HH- and LH-NDM were 23.02 and $24.94 \mathrm{~min}$ at $75^{\circ} \mathrm{C}, 10.45$ and $12.54 \mathrm{~min}$ at $80^{\circ} \mathrm{C}, 8.63$ and $8.68 \mathrm{~min}$ at $85^{\circ} \mathrm{C}$, and 5.82 and $4.55 \mathrm{~min}$ at $90^{\circ} \mathrm{C}$, respectively. The predicted and observed destruction of C. sakazakii and Salmonella spp. were in agreement, indicating that the behavior of the organisms was similar regardless of the heat-

Received December 20, 2013.

Accepted August 19, 2014.

${ }^{1}$ Corresponding author: kschmidt@ksu.edu ing system (conventional vs. RFDH). Radio-frequency dielectric heating can be used as a faster and more uniform heating method for NDM to achieve target temperatures for a postprocess lethality treatment of NDM before packaging.

Key words: radio-frequency dielectric heating, nonfat dry milk, Cronobacter sakazakii, Salmonella species

\section{INTRODUCTION}

Nonfat dry milk is a widely used dairy product that can be consumed directly or used as an ingredient in various food products, including powdered infant formula (PIF). Neither NDM nor PIF are sterile, and the possibility of postpasteurization contamination of milk cannot be ruled out (Olsen et al., 2004; Brooks, 2010). Cronobacter sakazakii and Salmonella spp. have been associated with several sporadic outbreaks due to contaminated NDM and PIF (Bowen and Braden, 2006; Cahill et al., 2008; Astley, 2012) and have been isolated from NDM and PIF products (Louie et al., 1993; Iversen and Forsythe, 2004; Flynn, 2011). Although C. sakazakii and Salmonella spp. cannot survive milk pasteurization (Read et al., 1968; Osaili et al., 2009), they can survive spray-drying temperatures if postpasteurization contamination of the milk occurs (LiCari and Potter, 1970; Arku et al., 2008).

Both C. sakazakii and Salmonella spp. have been classified as class A pathogens (clear evidence of causality) in PIF (FAO/WHO, 2004a,b). Cronobacter sakazakii can result in life-threatening infections in infants such as bacteremia, meningitis, sepsis, cerebritis, and necrotizing enterocolitis (FAO/WHO, 2004a; Fiore et al., 2008; Lehner, 2010), and Salmonella spp. can cause severe diarrhea in infants that can result in death (FAO/ WHO, 2004a).

Radio-frequency dielectric heating (RFDH) is an electro-heating process in which electric energy is converted into electromagnetic waves that subsequently generate volumetric heat within a product (Rowley, 2001; Piyasena et al., 2003; Marra et al., 2009). Foods consist of dipoles (such as water) and ions (such as 
salts), which contribute to heat generation within a food product during RFDH (FDA, 2000). During RFDH treatment, a food product is placed between the capacitor plates of an RFDH unit and an alternating electric field is applied. Frictional heat is generated within the food product due to (1) dipole rotation (the dipoles in the food align themselves along the electric field and oscillate continuously along the changing electric field), and (2) ionic depolarization (the ions in the food move toward the opposite charged regions of the electric field and migrate continuously according to the changing electric field; Piyasena et al., 2003; Ramaswamy and Tang, 2008; Marra et al., 2009). Because radio frequencies can interfere with radar and communication systems, the frequencies approved by Electromagnetic Compatibility Regulations and Federal Communications Commission for industrial, scientific, and medical applications are $13.56 \pm 0.00678,27.12 \pm 0.16272$, and $40.68 \pm 0.02034$ $\mathrm{MHz}$ (FDA, 2000; Rowley, 2001; Marra et al., 2009). The advantages of RFDH over conventional heating are better volumetric heating, more uniform heating, greater penetration power, lower surface overheating, fewer cold spots, shorter treatment time, improved energy efficiency, and better process control (FDA, 2000; Marra et al., 2009).

Although RFDH is used in baking, drying, and defrosting, commercial applications for food pasteurization and sterilization are scarce in North America (FDA, 2000; Rowley, 2001; Ramaswamy and Tang, 2008). Research on RFDH applications for the thermal inactivation of foodborne pathogens has been explored in mashed potatoes for Clostridium sporogenes (Luechapattanaporn et al., 2004), scrambled eggs for C. sporogenes (Luechapattanaporn et al., 2005), milk for E. coli and Listeria innocua (Awuah et al., 2005), ground beef for E. coli (Guo et al., 2006), apple cider for E. coli (Geveke and Brunkhorst, 2008), and pork luncheon meat for Bacillus cereus and C. perfringens (Byrne et al., 2010). Reports on C. sakazakii and Salmonella spp. in NDM or PIF suitable for commercial application are nonexistent. Prior research on destruction of these pathogens in NDM and PIF was done either in liquid-rehydrated systems or at temperatures $\leq 70^{\circ} \mathrm{C}$ (Iversen at al., 2004; Kim and Park, 2007; Walsh et al., 2011). Therefore, the objective of this study was to determine the thermal processing parameters (decimal reduction time, D-value, at $75,80,85$, and $90^{\circ} \mathrm{C}$; and thermal resistance constant, $z$-value) of $C$. sakazakii and Salmonella spp. in high-heat (HH) and low-heat (LH) NDM using a water bath and thermaldeath-time (TDT) disks; and to validate an RFDH system for decontamination of NDM. Because HH- and LH-NDM are used for different applications in various food products, both were included in this study.

\section{MATERIALS AND METHODS}

\section{Experimental Design}

A 5-strain cocktail of C. sakazakii or Salmonella spp. was used in this study because both of the organisms have been implicated in outbreaks from contaminated NDM. The D- and z-values of C. sakazakii or Salmonella spp. in HH-NDM (ConAgra Foods, Menomonie, WI) and LH-NDM (Dairy America, Fresno, CA) were first determined using custom-designed stainless steel TDT disks $(6.0 \mathrm{~cm}$ in diameter and $0.5 \mathrm{~cm}$ high; University of Nebraska, Lincoln) and a hot-water bath (Precision Scientific, Chicago, IL). On the basis of results obtained from the TDT disks, the RFDH experiment was designed to validate microbial destruction. The TDT disks and RFDH studies were considered independent experiments; HH- and LH-NDM were inoculated and heat-treated randomly. Three replications were conducted for all treatments, and each microbial enumeration was done in duplicate. Linear regression graphs were plotted using SAS version 9.1 (SAS Institute Inc., Cary, NC). All comparisons for C. sakazakii or Salmonella spp. in HH- and LH-NDM at respective temperatures were conducted with Student's $t$-test at $P$ $\leq 0.05$ in SAS 9.1 (SAS Institute Inc.).

\section{Bacterial Cultures}

Cronobacter sakazakii and Salmonella spp. strains were selected based on risk and involvement in outbreaks associated with NDM or PIF, isolated from food processing plants, and used in published research. Cronobacter sakazakii 29544 and BAA-894 were obtained from the American Type Culture Collection (ATCC, Manassas, VA), and 1 environmental isolate and 2 processing-plant isolates of $C$. sakazakii were obtained from Applied Food Safety Laboratory, University of Nebraska (Lincoln). Salmonella serovars Agona BAA-707, Tennessee 10722, and Typhimurium 13311 were obtained from ATCC, and Salmonella Montevideo and Senftenberg (processing plant isolates) were obtained from the Food Safety and Defense Laboratory, Kansas State University (Manhattan). All strain designations were confirmed using API 20E (bioMérieux, Durham, NC).

\section{Inoculum Preparation and Inoculation Procedure}

All organisms were individually grown on tryptic soy agar (TSA; Difco, Becton, Dickinson Co., Sparks, $\mathrm{MD}$ ), and isolated colonies were maintained at $4^{\circ} \mathrm{C}$ on TSA plates. An individual colony of each strain was transferred from TSA to $10 \mathrm{~mL}$ of tryptic soy broth 

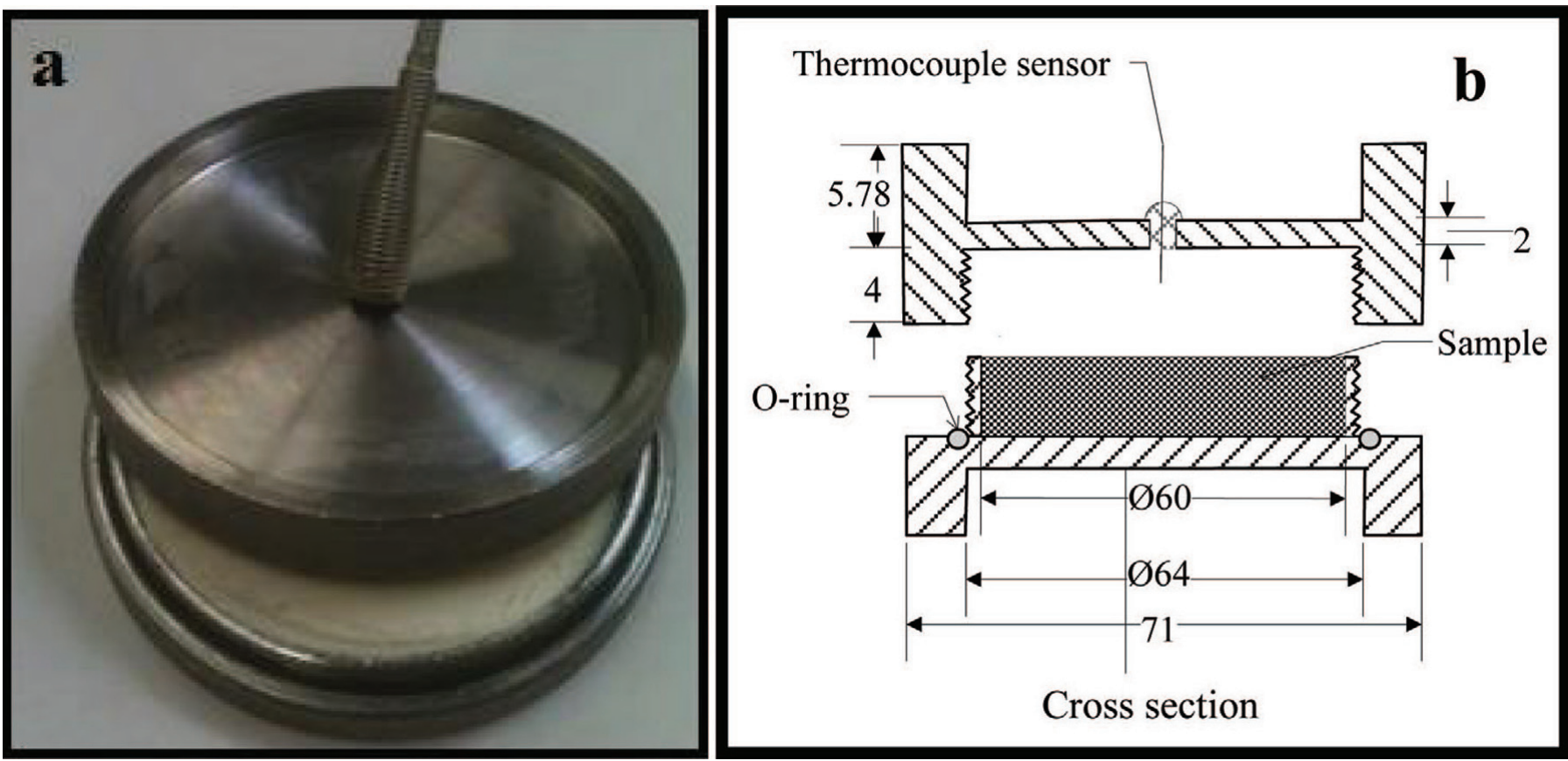

Figure 1. Thermal-death-time disk (a) containing inoculated NDM and connected to a thermocouple; and (b) schematic. Color version available in the online PDF.

(Difco) and incubated at $37^{\circ} \mathrm{C}$ for $24 \mathrm{~h}$. A loop $(25 \mu \mathrm{L})$ of each strain was individually transferred into $40 \mathrm{~mL}$ of tryptic soy broth in centrifuge tubes and incubated at $37^{\circ} \mathrm{C}$ for $24 \mathrm{~h}$. Strains were then centrifuged at 5,520 $\times g$ and $-4^{\circ} \mathrm{C}$ for $15 \mathrm{~min}$, the supernatant was discarded, and pellets were reconstituted in $40 \mathrm{~mL}$ of $0.1 \%$ peptone water (Difco). Five strains of C. sakazakii or Salmonella spp. were mixed and transferred into separate, sanitized spray bottles $(300 \mathrm{~mL})$.

High-heat or LH-NDM in sanitized plastic tubs (9.4 L, Rubbermaid, Atlanta, GA) was inoculated with a 5-strain cocktail of C. sakazakii or Salmonella spp. by spraying 1 squirt $(\sim 0.8 \mathrm{~mL})$ per $10 \mathrm{~g}$ of NDM. Inoculated NDM was dried with open lids at $37^{\circ} \mathrm{C}$ for $24 \mathrm{~h}$ (to achieve the original moisture content of NDM; data not presented), and then ground using a food processor (Ninja, Euro-Pro Operating LLC, Boston, MA) for 1 min to homogenize the inoculum.

\section{Heat Treatment}

TDT Disks. The TDT disks (Figure 1) used in this study were similar to those used by Jin et al. (2008); however, the disks in this study were manufactured from stainless steel instead of aluminum. Eight grams of inoculated NDM was placed in a sanitized TDT disk, sealed, and transferred to a hot-water bath (preset at $75,80,85$, or $90^{\circ} \mathrm{C}$ ). Temperatures of samples (in TDT disks) and the hot-water bath were monitored using thermocouples (Hypodermic Needle Probes, Omega Engineering Inc., Stamford, CT) and a data logger (Measurement Computing USB-TC and MCC DAQ Software, Norton, MA). Once the target temperatures were reached, samples were held for 0 to $80 \mathrm{~min}$ and then transferred from the hot-water bath to a coldwater bath $\left(\sim 4^{\circ} \mathrm{C}\right)$ at specific time intervals. The processed samples were cooled to $\sim 10^{\circ} \mathrm{C}$ and immediately enumerated for C. sakazakii or Salmonella spp.

$\boldsymbol{R} \boldsymbol{F} \boldsymbol{D H}$. Inoculated HH-NDM (5 g) or LH-NDM (7 g) was placed in a sanitized circular container (Aqua Lab, Decagon, Pullman, WA), covered with a lid, and then wrapped in Parafilm M (Pechiney Plastic Packaging, Chicago, IL). The sealed, inoculated container was placed at the center of the circular high-density polyethylene tray $(0.3 \mathrm{~cm}$ thick, $22.4 \mathrm{~cm}$ in diameter, and 2.1 cm high; Dynalab Corp., Rochester, NY) along with a noninoculated sample container (Figure 2a) to monitor the temperature using a fiber-optic probe (T1, Neoptix Inc., Québec, Canada) and a data logger (Reflex, Neoptix Inc.). The circular tray was then filled with noninoculated HH- or LH-NDM, and the product surface in the tray was leveled (with a $30-\mathrm{cm}$ ruler) to a height of $2.1 \mathrm{~cm}$ (Figure 2b). Samples were heated in the RFDH unit (Figure 3; Strayfield Limited, Theale, UK) set at a frequency of $27.12 \mathrm{MHz}$, power of $3 \mathrm{~kW}$, and electrode distance of $120 \mathrm{~mm}$ until target temperatures were achieved. Samples were then transferred to a convection oven (Thelco, GCA/Precision Scientific, Schaar 


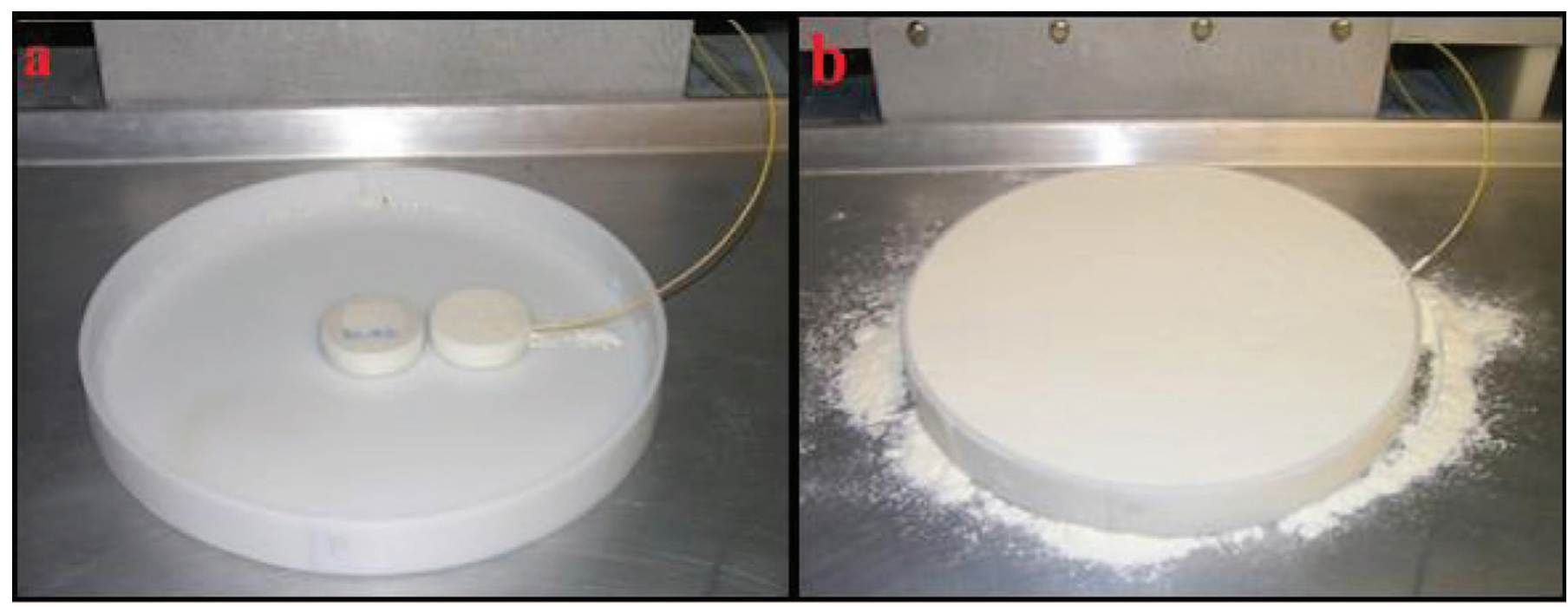

Figure 2. Inoculated and noninoculated (connected to fiber-optic probe) NDM in sealed containers in high-density polyethylene tray for radio-frequency dielectric heating: (a) before covering with noninoculated NDM; and (b) after covering with noninoculated NDM. Color version available in the online PDF.

Scientific Company, Chicago, IL) pre-set at the designated temperatures for specific time periods. Processed samples were then transferred to a cold-water $\left(\sim 4^{\circ} \mathrm{C}\right)$ bath. The samples were cooled to $\sim 10^{\circ} \mathrm{C}$ and immediately enumerated for C. sakazakii or Salmonella spp.

\section{Microbial Enumeration}

The treated product ( 5 or $7 \mathrm{~g}$ ) was transferred to a stomacher bag to which 45 or $43 \mathrm{~mL}$ of peptone water $(0.1 \%)$ was added. The sample was mixed by stomacher (Smasher, AES Laboratoire, Bruz, France) for $1 \mathrm{~min}$, and serial dilutions (1:10) were subsequently prepared using peptone water. The samples were spread-plated on TSA and incubated at $37^{\circ} \mathrm{C}$ for $24 \mathrm{~h}$. Noninoculated HH- and LH-NDM were also plated on TSA to determine the background microbial load and the presence of C. sakazakii and Salmonella spp.

\section{Determination of $D$ - and z-Values}

Regression lines were generated from the log of viable microbes versus time, and D-values were calculated as absolute values of inverse of the slopes. For $z$-values, regression lines were generated from the log of D-values versus temperatures, and $z$-values were calculated as absolute values of inverses of the slopes (Al-Holy et al., 2009).

\section{Observed Versus Predicted Microbial Destruction}

On the basis of thermal destruction parameters (obtained from TDT disk study), the times required to achieve 3-log reduction (predicted log reduction) of $C$. sakazakii and Salmonella spp. in HH- and LH-NDM were calculated. The RFDH study was then conducted to validate the $\log$ reduction (observed log reduction) of C. sakazakii and Salmonella spp. in HH- and LHNDM at respective temperatures for calculated times. The observed reductions of C. sakazakii and Salmonella spp. were plotted against predicted reductions and compared.

\section{RESULTS AND DISCUSSION}

Mean times required for NDM to achieve the target temperatures in the TDT disks and RFDH unit from an initial temperature of $\sim 27^{\circ} \mathrm{C}$ are presented in Table 1. For all the temperatures, the time required to achieve the target temperatures was less $(P \leq 0.05)$ in the RFDH unit compared with TDT disks (Table 1). These results confirmed that RFDH can heat a lowmoisture food product faster than conventional heating methods. In the TDT disks, heat was transferred mainly by conduction between TDT disks and NDM, whereas in the RFDH unit, heat was generated within NDM by dielectric heating.

The initial total plate counts in HH- and LH-NDM were $2.05 \pm 0.05$ and $2.41 \pm 0.06 \log \mathrm{cfu} / \mathrm{g}(\mathrm{n}=3)$, respectively (which were within the standards; $<4 \log$ cfu/g; USDEC, 2010), and the samples were negative for C. sakazakii and Salmonella spp. (detection limit of $1 \log \mathrm{cfu} / \mathrm{g}$ ). The thermal inactivation of C. sakazakii and Salmonella spp. in HH- and LH-NDM using TDT disks is presented in Figures 4 and 5. The TDT curves 
Table 1. Time ( $\mathrm{min})$ required to achieve the target temperatures for NDM in thermal-death-time (TDT) disks and radio-frequency dielectric heating $(\mathrm{RFDH}) \mathrm{unit}^{1}$

\begin{tabular}{lccrr}
\hline & \multicolumn{4}{c}{ Temperature $\left({ }^{\circ} \mathrm{C}\right)$} \\
\cline { 2 - 4 } Heating method & 75 & 80 & 85 & 90 \\
\hline TDT disks & $7.94 \pm 0.96^{\mathrm{a}}$ & $9.51 \pm 1.11^{\mathrm{a}}$ & $8.86 \pm 0.72^{\mathrm{a}}$ & $10.72 \pm 0.87^{\mathrm{a}}$ \\
RFDH & $4.26 \pm 0.23^{\mathrm{b}}$ & $4.54 \pm 0.32^{\mathrm{b}}$ & $4.95 \pm 0.30^{\mathrm{b}}$ & $5.50 \pm 0.38^{\mathrm{b}}$ \\
\hline${ }^{\mathrm{a}, \mathrm{b}}$ Values within a column differ significantly $(P \leq 0.05)$. & \\
${ }^{1}$ Mean \pm SE $(\mathrm{n}=3)$.
\end{tabular}

( $\log$ of $\mathrm{D}$-value vs. temperature) were used to calculate $z$-values (Figure 6).

The initial counts of $C$. sakazakii or Salmonella spp. in inoculated NDM were $\sim 6.0 \mathrm{log} \mathrm{cfu} / \mathrm{g}$ (data not shown). The D-values of C. sakazakii or Salmonella spp. for HH- and LH-NDM at the same temperatures were similar $(P>0.05)$, except for C. sakazakii in HH- and LH-NDM at $80^{\circ} \mathrm{C}$ (Table 2). The D-values of C. sakazakii and Salmonella spp. varied from 23.00 to $26.25 \mathrm{~min}$ at $75^{\circ} \mathrm{C}, 7.52$ to $13.75 \mathrm{~min}$ at $80^{\circ} \mathrm{C}, 6.03$ to $8.68 \mathrm{~min}$ at $85^{\circ} \mathrm{C}$, and 3.05 to $5.82 \mathrm{~min}$ at $90^{\circ} \mathrm{C}$, respectively (Table 2 ). The $z$-values of C. sakazakii in HH- and LH-NDM were 23.77 and $26.28^{\circ} \mathrm{C}$, respectively, whereas $z$-values of Salmonella spp. in HH- and LH-NDM were 26.92 and $20.92^{\circ} \mathrm{C}$, respectively (Table 2 ).
Observed log reductions were in agreement with predicted log reductions (Figure 7), except that observed $\log$ reductions of C. sakazakii in HH- and LH-NDM at $90^{\circ} \mathrm{C}$ and Salmonella spp. in $\mathrm{HH}-\mathrm{NDM}$ at $90^{\circ} \mathrm{C}$ were $>1.5 \mathrm{log} \mathrm{cfu} / \mathrm{g}$ compared with predicted reductions. Overall, the predicted and observed log reductions for $C$. sakazakii and Salmonella spp. were similar using TDT disks and RFDH methods, indicating that destruction of organisms is mainly due to the thermal effect. The RFDH reduced the time to achieve the target temperatures compared with conventional heating. Geveke et al. (2007), however, reported that RFDH treatment of pulp-free orange juice at $21.1 \mathrm{kHz}$ and $60^{\circ} \mathrm{C}$ reduced the Escherichia coli K12 population by $2.1 \log \mathrm{cfu} / \mathrm{mL}$, whereas the $E$. coli population did not decrease when

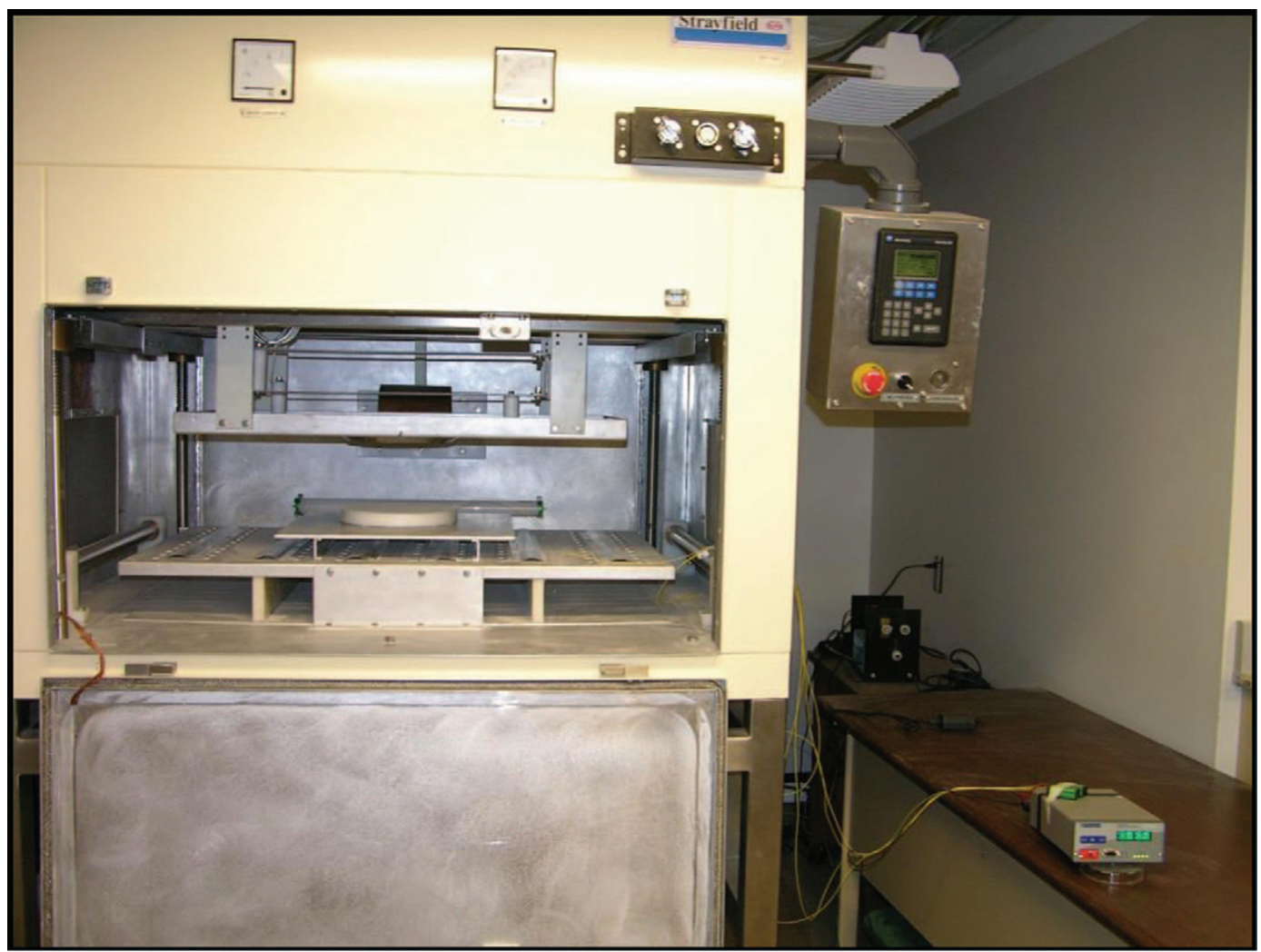

Figure 3. Radio-frequency dielectric heating unit. Color version available in the online PDF. 

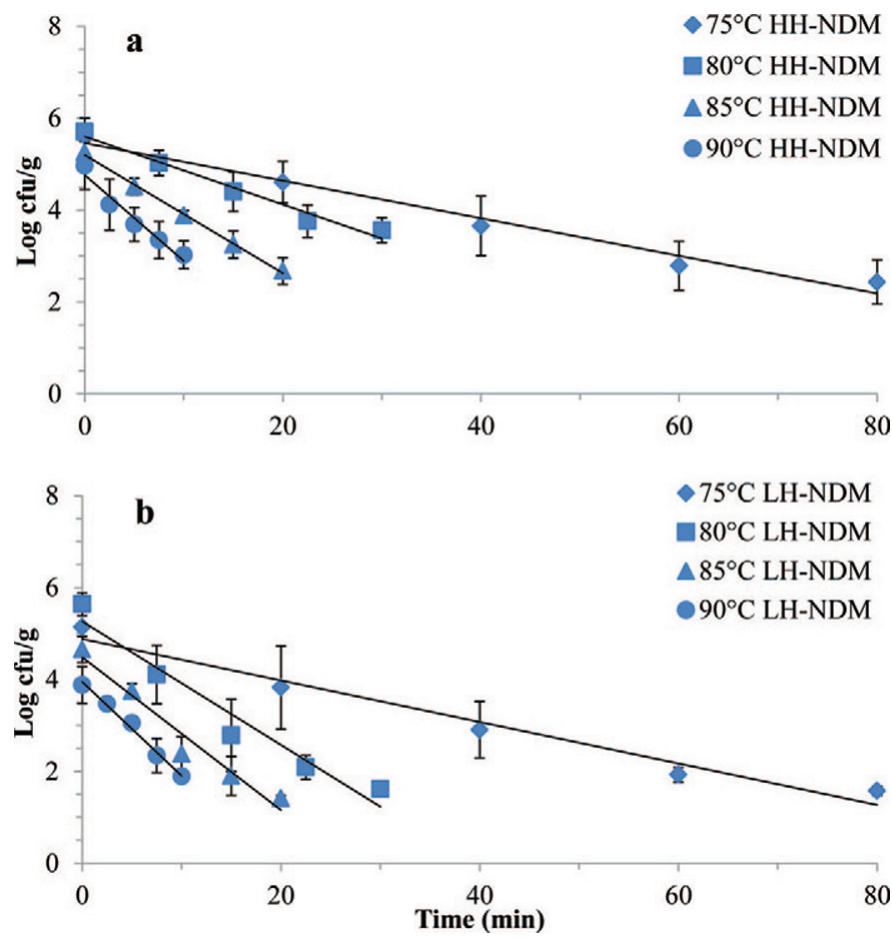

Figure 4. Thermal inactivation of Cronobacter sakazakii using thermal-death-time disks at $75,80,85$, and $90^{\circ} \mathrm{C}$ in high-heat $(\mathrm{HH})$ and low-heat (LH) NDM. Error bars indicate SE. Color version available in the online PDF.

juice was heated at $60^{\circ} \mathrm{C}$ using the conventional method, suggesting that nonthermal effects could contribute to these differences. Geveke and Brunkhorst (2008) reported that the E. coli K12 population in apple cider was reduced by $4.8 \log \mathrm{cfu} / \mathrm{mL}$ by $\mathrm{RFDH}$ at $60^{\circ} \mathrm{C}$ and $21 \mathrm{kHz}$ compared with no reduction using conventional heating at $60^{\circ} \mathrm{C}$. Ukuku et al. (2012) suggested that nonthermal effects of RFDH on microbial cells could be due to the decrease in the microbial cell surface hydrophobicity and loss of negative ions.

Thermal inactivation data of C. sakazakii and Salmonella spp. in NDM or foods with low water activity (at the temperatures investigated in this study) are not available in the literature. The published thermal destruction parameters for C. sakazakii and Salmonella spp. in various dry products were derived from experiments conducted either at temperatures $\leq 70^{\circ} \mathrm{C}$ or as rehydrated products (such as infant formula). Lound et al. (2011) reported that D-values of non-acid-adapted Salmonella Typhimurium in powdered egg albumin heat-treated in a hot water bath were 99.56, 43.90, and 15.54 min at 72,77 , and $82^{\circ} \mathrm{C}$, respectively. These Dvalues were greater than the $\mathrm{D}$-values for Salmonella spp. in NDM at 75,80 , and $85^{\circ} \mathrm{C}$ in the current study. Perhaps the differences in Salmonella spp. serovars or strains used or inoculation procedures [dried at $50^{\circ} \mathrm{C}$ after spray inoculation before heat treatment by Lound et al. (2011) vs. dried at $37^{\circ} \mathrm{C}$ after spray inoculation in this study] could have contributed to the differences in D-values. In addition, compositional (e.g., proteins, carbohydrates, fat) differences between egg albumin and NDM could contribute to these differences in the D-values of Salmonella spp. VanCauwenberge et al. (1981) reported variability in D-values at $49^{\circ} \mathrm{C}$ for $\mathrm{Sal}$ monella spp. (8 different serotypes) in corn flour, which ranged from 18 to $594 \mathrm{~min}$.

Luechapattanaporn et al. (2004) reported that Dvalues of Clostridium sporogenes (PA3679) in mashed potatoes (water activity $=0.998$ ), using TDT tubes submerged in a heated oil bath, ranged from 2.16 to $0.61 \mathrm{~min}$ at 115.6 to $121.1^{\circ} \mathrm{C}$. From this data, they calculated $\mathrm{F}_{\mathrm{o}}$ values (time required to destroy specific microorganisms in specified medium at $121.1^{\circ} \mathrm{C}$ ), which validated the microbial destruction using RFDH. Luechapattanaporn et al. (2005) used the same procedure to validate D-values with RFDH but using scrambled eggs as the medium; moreover, both studies of Luechapattanaporn et al. (2004, 2005) maintained the samples in an RFDH unit submerged in a water chamber to reduce the fringe (or edge) effect during the entire process. In our study, samples were transferred to a
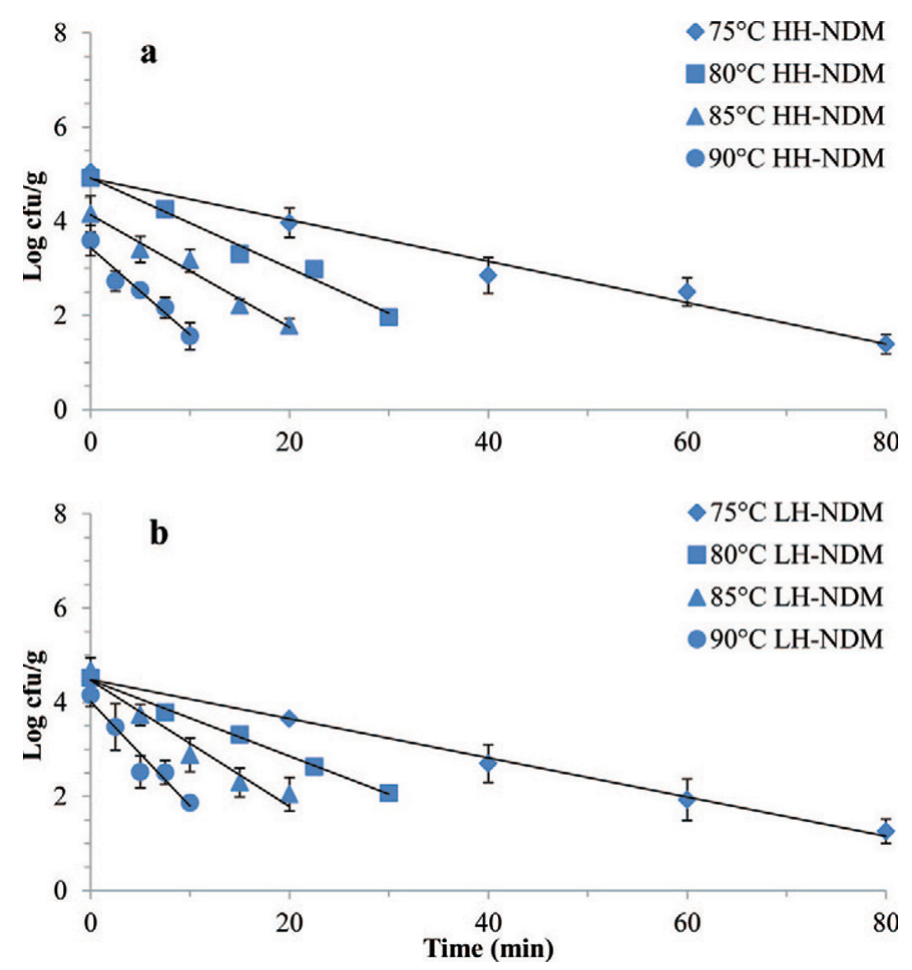

Figure 5. Thermal inactivation of Salmonella spp. using thermaldeath-time disks at $75,80,85$, and $90^{\circ} \mathrm{C}$ in high-heat $(\mathrm{HH})$ and lowheat (LH) NDM. Error bars indicate SE. Color version available in the online PDF. 
Table 2. The D-values (decimal reduction time; min) and $z$-values (temperature increase required to obtain a decimal reduction of the D-value; ${ }^{\circ} \mathrm{C}$ ) of Cronobacter sakazakii and Salmonella spp. in high-heat (HH) and low-heat (LH) NDM heated in thermal-death-time disks ${ }^{1}$

\begin{tabular}{lcccrr}
\hline & \multicolumn{2}{c}{ C. sakazakii } & & \multicolumn{2}{c}{ Salmonella spp. } \\
\cline { 2 - 3 } \cline { 5 - 6 } Item & HH-NDM & LH-NDM & & HH-NDM & LH-NDM \\
\hline Temperature $\left({ }^{\circ} \mathrm{C}\right)$ & & & & \\
75 & $24.86 \pm 2.33$ & $23.00 \pm 3.17$ & & $23.02 \pm 1.53$ & $24.94 \pm 3.50$ \\
80 & $13.75 \pm 1.22^{\mathrm{a}}$ & $7.52 \pm 0.48^{\mathrm{b}}$ & & $10.45 \pm 0.15$ & $12.54 \pm 0.98$ \\
85 & $8.00 \pm 0.93$ & $6.03 \pm 0.24$ & & $8.63 \pm 1.04$ & $8.68 \pm 2.61$ \\
90 & $5.57 \pm 0.79$ & $5.37 \pm 1.24$ & & $5.82 \pm 1.18$ & $4.55 \pm 0.33$ \\
$z$-value & $23.77 \pm 3.70$ & $26.28 \pm 4.73$ & & $26.92 \pm 3.65$ & $20.92 \pm 0.40$ \\
\hline
\end{tabular}

${ }^{\mathrm{a}, \mathrm{b}}$ Values within a row and under respective species differ significantly $(P \leq 0.05)$.

${ }^{1}$ Mean \pm SE $(\mathrm{n}=3)$.

convection oven for process time after attaining the target temperatures in RFDH. Mashed potatoes and scrambled egg obviously had greater moisture contents than $\operatorname{NDM}(<5 \%)$, plus the microorganisms differed. Products with greater moisture contents have greater dielectric constants and loss factors, which result in greater conversion of radio frequencies into thermal energy compared with products with low moisture contents (Komarov et al., 2005).

Chen et al. (2013) studied the functional properties of HH- and LH-NDM by heating NDM in a RFDH unit to $75,80,85$, and $90^{\circ} \mathrm{C}$ and holding the samples in a convection oven up to $125.67,57.75,25.0$, and 11.50 min, respectively. They reported that whey protein nitrogen indices (WPNI) of heat-treated HH-NDM samples were similar to that of nonheated control (1.48 $\mathrm{mg} / \mathrm{g}$ ) and ranged from 1.32 to $1.48 \mathrm{mg} / \mathrm{g}$; however, WPNI of HH-NDM heated at $80^{\circ} \mathrm{C}$ for $57.75 \mathrm{~min}$ and at $85^{\circ} \mathrm{C}$ for 10 and $25 \mathrm{~min}$ (1.32 to $1.34 \mathrm{mg} / \mathrm{g}$ ) were lower than that of nonheated control. Chen et al. (2013) also reported that the WPNI of LH-NDM heated at

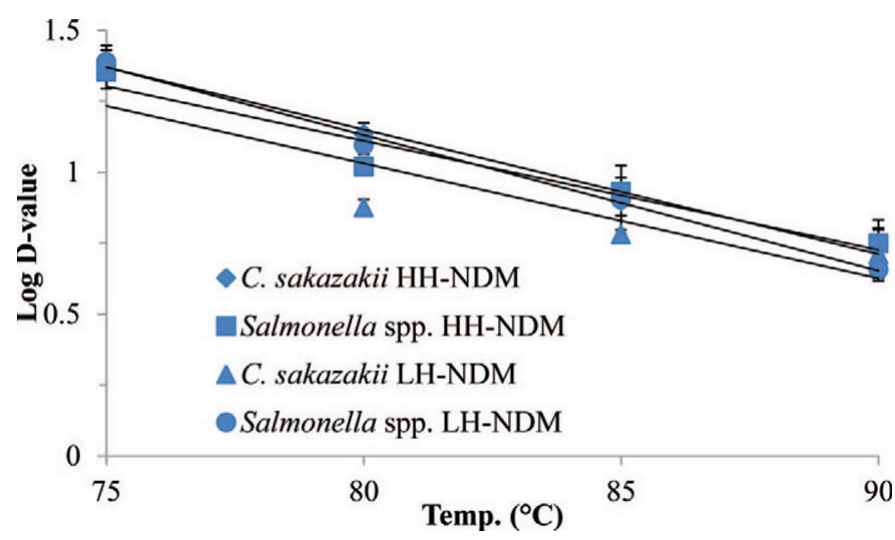

Figure 6. Log D-value (decimal reduction time) versus temperature for Cronobacter sakazakii and Salmonella spp. in high-heat (HH) and low-heat (LH) NDM using thermal-death-time disks. Error bars indicate SE. Color version available in the online PDF. temperatures $\geq 80^{\circ} \mathrm{C}$ (5.78 to $6.48 \mathrm{mg} / \mathrm{g}$ ) were lower than that of nonheated control $(7.24 \mathrm{mg} / \mathrm{g})$. Although WPNI of some NDM differed $(P \leq 0.05)$ from the nonheated controls, all samples maintained their classification standards ( $>6 \mathrm{mg} / \mathrm{g}$ for HH-NDM, and $<1.5$ $\mathrm{mg} / \mathrm{g}$ for LH-NDM), except for LH-NDM heated at $85^{\circ} \mathrm{C}$ for $25 \mathrm{~min}$. Nitrogen solubility indices (NSI) of all
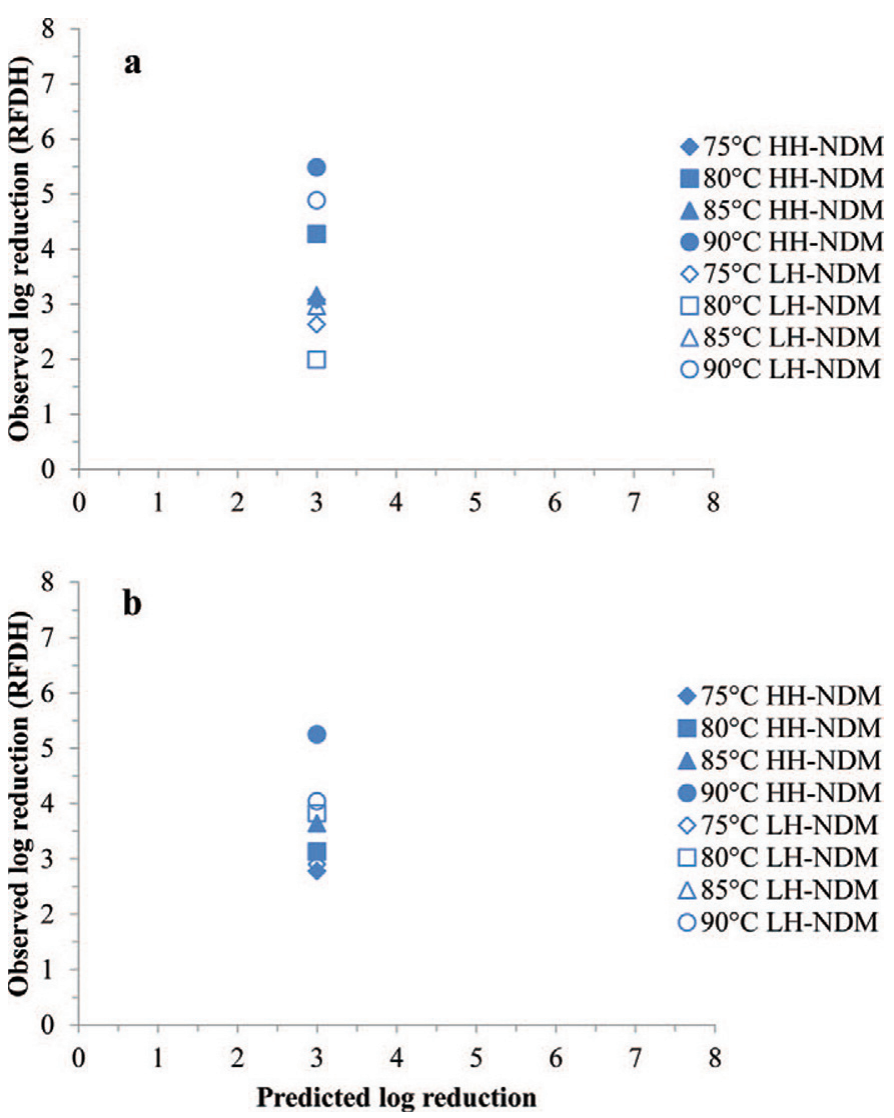

Figure 7. Predicted versus observed log reductions of (a) Cronobacter sakazakii, and (b) Salmonella spp. in high-heat (HH) and low-heat (LH) NDM. RFDH = radio-frequency dielectric heating. Color version available in the online PDF. 
heated NDM at temperatures $\geq 80^{\circ} \mathrm{C}$ were lower $(89.0$ to $87.9 \%$ and 88.3 to $89.4 \%$ for $\mathrm{HH}$ - and LH-NDM, respectively; $P \leq 0.05)$ than that of nonheated controls (90.6 and $93.3 \%$ for HH- and LH-NDM, respectively). Chen et al. (2013) also reported that color of HH-NDM was not affected by heat treatment, except that HH$\mathrm{NDM}$ heated at $90^{\circ} \mathrm{C}$ for 0 min (yellow-blue color, $\mathrm{b}^{*}$ $=13.27$ ) was yellower than that of nonheated control $\left(b^{*}=11.46\right)$. Low heat-NDM was also not affected by the heat treatment, except that LH-NDM heated at 75 and $85^{\circ} \mathrm{C}$ for 25 and $10 \mathrm{~min}$, respectively (red-green color, $\mathrm{a}^{*}=-2.51$ and -2.44 , respectively) were greener than nonheated control $\left(\mathrm{a}^{*}=-1.89\right)$, and LH-NDM heated at $90^{\circ} \mathrm{C}$ for $0 \mathrm{~min}\left(\mathrm{~b}^{*}=14.43\right)$ was yellower than nonheated control $\left(\mathrm{b}^{*}=12.27\right)$.

\section{CONCLUSIONS}

Treatment by RFDH can be used to heat NDM, thus shortening the overall postprocess lethality treatment before packaging, and to minimize food safety risk. The effects of RFDH on the functional properties of NDM, such as WPNI, solubility, color, and flowability, should also be evaluated. Thermal resistance of $C$. sakazakii and Salmonella spp. in NDM should be further validated under commercial conditions.

\section{ACKNOWLEDGMENTS}

We acknowledge Dairy Management Inc. (Rosemont, IL) for funding this research, and Kansas State University Research and Extension (Manhattan). This is contribution number 14-188-J from the Kansas Agriculture Experiment Station.

\section{REFERENCES}

Al-Holy, M. A., M. Lin, M. M. Abu-Ghoush, H. M. Qadiri, and B. A. Rasco. 2009. Thermal resistance, survival and inactivation of Enterobacter sakazakii (Cronobacter spp.) in powdered and reconstituted infant formula. J. Food Saf. 29:287-301.

Arku, B., N. Mullane, E. Fox, S. Fanning, and K. Jordan. 2008. Enterobacter sakazakii survives spray drying. Int. J. Dairy Sci. 61:102-108.

Astley,M. 2012. Belgium baby formula-linked Salmonella outbreaksickens 16 in Russia. Food Quality News. Accessed Mar. 1, 2013. http://www. foodqualitynews.com/Food-Alerts/Belgian-baby-formula-linkedSalmonella-outbreak-sickens-16-in-Russia.

Awuah, G. B., H. S. Ramaswamy, A. Economides, and K. Mallikarjunan. 2005. Inactivation of Escherichia coli K-12 and Listeria innocua in milk using radio frequency (RF) heating. Innov. Food Sci. Emerg. Technol. 6:396-402.

Bowen, A. B., and C. R. Braden. 2006. Invasive Enterobacter sakazakii disease in infants. Emerg. Infect. Dis. 12:1185-1189.

Brooks, J. 2010. On Cronobacter sakazakii. Food Safety News. Accessed Mar. 1, 2013. http://www.foodsafetynews.com/2010/06/ on-cronobacter-sakazakii/.

Byrne, B., J. G. Lyng, G. Dunne, and D. J. Bolton. 2010. Radio frequency heating of comminuted meats - considerations in relation to microbial challenge studies. Food Contr. 21:125-131.
Cahill, S. M., I. K. Wachsmuth, M. de Lourdes Costarrica, and P. K. Ben Embarek. 2008. Powdered infant formula as a source of Salmonella infection in infants. Clin. Infect. Dis. 46:268-273.

Chen, C., M. Michael, R. K. Phebus, H. Thippareddi, J. Subbiah, S. L. Birla, and K. A. Schmidt. 2013. Radio-frequency dielectric heating of nonfat dry milk affects solubility and whey protein nitrogen index. J. Dairy Sci. 96:1471-1476.

FAO/WHO (Food and Agriculture Organization, and World Health Organization of the United Nations). 2004a. Enterobacter sakazakii and other microorganisms in powdered infant formula: Meeting report. Microbial Risk Assessment Series 6. Accessed Mar. 1, 2013. http://www.fao.org/docrep/007/y5502e/y5502e00.htm.

FAO/WHO (Food and Agriculture Organization, and World Health Organization of the United Nations). 2004b. Enterobacter sakazakii and Salmonella in powdered infant formula: Meeting report. Microbial Risk Assessment Series 6. Accessed Mar. 1, 2013. ftp:// ftp.fao.org/docrep/fao/009/a0707e/a0707e00.pdf.

FDA (Food and Drug Administration). 2000. Microwave and radio frequency. In Kinetics of microbial inactivation for alternative food processing technologies. Accessed Mar. 1, 2013. http://www.fda.gov/ Food/FoodScienceResearch/SafePracticesforFoodProcesses/ucm 100250.htm.

Fiore, A., M. Casale, and P. Aureli. 2008. Enterobacter sakazakii: Epidemiology, clinical presentation, prevention and control. Ann. Ist. Super. Sanita 44:275-280.

Flynn, D. 2011. Salmonella found inside Minnesota milk plant. Food Safety News. Accessed Mar. 1, 2013. http://www.foodsafetynews. com/2011/02/salmonella-contamination-found-inside-minnesotadairy/.

Geveke, D. J., and C. Brunkhorst. 2008. Radio frequency electric fields inactivation of Escherichia coli in apple cider. J. Food Eng. $85: 215-221$

Geveke, D. J., C. Brunkhorst, and X. Fan. 2007. Radio frequency electric fields processing of orange juice. Innov. Food Sci. Emerg. Technol. 8:549-554.

Guo, Q., P. Piyasena, G. S. Mittal, W. Si, and J. Gong. 2006. Efficacy of radio frequency cooking in the reduction of Escherichia coli and shelf stability of ground beef. Food Microbiol. 23:112-118.

Iversen, C., and S. Forsythe. 2004. Isolation of Enterobacter sakazakii and other Enterobacteriaceae from powdered infant formula milk and related products. Food Microbiol. 221:771-777.

Iversen, C., M. Lane, and S. J. Forsythe. 2004. The growth profile, thermotolerance and biofilm formation of Enterobacter sakazakii grown in infant formula milk. Lett. Appl. Microbiol. 38:378-382.

Jin, T., H. Zhang, G. Boyd, and J. Tang. 2008. Thermal resistance of Salmonella enteritidis and Escherichia coli K12 in liquid egg determined by thermal-death-time disks. J. Food Eng. 84:608-614.

Kim, S.-H., and J.-H. Park. 2007. Thermal resistance and inactivation of Enterobacter sakazakii isolates during rehydration of powdered infant formula. J. Microbiol. Biotechnol. 17:364-368.

Komarov, V., S. Wang, and L. Tang. 2005. Permittivity and measurement. Pages 3693-3711 in Encyclopedia of RF and Microwave Engineering. K. Chang, ed. John Wiley and Sons Inc., New York, NY.

Lehner, A. 2010. Cronobacter (former Enterobacter sakazakii) spp.Its effect in dairy product safety, quality and trade. Aust. J. Dairy Technol. 65:63-67.

LiCari, J. J., and N. N. Potter. 1970. Salmonella survival during spray drying and subsequent handling of skimmilk powder. II. Effects of drying conditions. J. Dairy Sci. 53:871-876.

Louie, K. K., A. M. Paccagnella, H. Lior, B. J. Francis, and M. T. Osterholm. 1993. Salmonella serotype Tennessee in powdered milk products and infant formula - Canada and United States, 1993. MMWR Morb. Mortal. Wkly. Rep. 42:516-517.

Lound, L., S. Plem, L. Favre, V. Genaro, F. Martinz, and L. Giannuzzi. 2011. Acid/heat resistance of Salmonella serotypes in powdered egg albumin. Proc. XXII Latin American Poult. Congr. Accessed Mar. 1, 2011. http://en.engormix.com/MA-poultry-industry/ health/articles/acid-heat-resistance-salmonella-t1838/165-p0.htm. 
Luechapattanaporn, K., Y. Wang, J. Wang, M. Al-Holy, D. H. Kang, J. Tang, and L. M. Hallberg. 2004. Microbial safety in radio-frequency processing of packaged foods. J. Food Sci. 69:M201-M206.

Luechapattanaporn, K., Y. Wang, J. Wang, J. Tang, L. M. Hallberg, and C. P. Dunne. 2005. Sterilization of scrambled eggs in military polymeric trays by radio frequency energy. J. Food Sci. 70:E288E294.

Marra, F., L. Zhang, and J. G. Lyng. 2009. Radio frequency treatment of foods: Review of recent advances. J. Food Eng. 91:497-508.

Olsen, S. J., M. Ying, M. F. Davis, M. Deasy, B. Holland, L. Iampietro, M. Baysinger, F. Sassano, L. D. Polk, B. Gormley, M. J. Hung, K. Pilot, M. Orsini, S. Van Duyne, S. Rakin, C. Genese, E. A. Bresnitz, J. Smucker, M. Moll, and J. Sobel. 2004. Multidrugresistant Salmonella Typhimurium infection from milk contaminated after pasteurization. Emerg. Infect. Dis. 10:932-935.

Osaili, T. M., R. R. Shaker, M. S. Al-Haddaq, A. A. Al-Nabulsi, and R. A. Holley. 2009. Heat resistance of Cronobacter species (Enterobacter sakazakii) in milk and special feeding formula. J. Appl. Microbiol. 107:928-935.

Piyasena, P., C. Dussault, T. Koutchma, H. S. Ramaswamy, and G. B. Awuah. 2003. Radio frequency heating of foods: Principles, applications and related properties - A review. Crit. Rev. Food Sci. Nutr. 43:587-606.
Ramaswamy, H., and J. Tang. 2008. Microwave and radio frequency heating. Food Sci. Technol. Int. 14:423-427.

Read, R. B., J. G. Bradshaw, R. W. Dickerson, and J. T. Peeler. 1968. Thermal resistance of Salmonellae isolated from dry milk. Appl. Microbiol. 16:998-1001.

Rowley, A. T. 2001. Radio frequency heating. Pages $163-177$ in Thermal Technology in Food Processing. P. Richardson, ed. Woodhead Publishing Ltd., Cambridge, UK.

Ukuku, D. O., D. J. Geveke, and P. H. Cooke. 2012. Effect of therma and radio frequency electric fields treatment on Escherichia coli bacteria in apple juice. J. Microbiol. Biochem. Technol. 4:76-81.

USDEC (United States Dairy Export Council). 2010. Nonfat dry milk and skimmed milk powder. Accessed Mar. 1, 2013. http://www. usdec.org/Products/content.cfm?ItemNumber $=82654 \&$ navItem Number $=82271$.

VanCauwenberge, J. E., R. J. Bothast, and W. F. Kwolek. 1981. Thermal inactivation of eight Salmonella serotypes on dry corn flour. Appl. Enivron. Microb. 42:688-691.

Walsh, D., C. Molloy, C. Iversen, J. Carroll, C. Cagney, S. Fanning, and G. Duffy. 2011. Survival characteristics of environmental and clinically derived strains of Cronobacter sakazakii in infant milk formula (IMF) and ingredients. J. Appl. Microbiol. 110:697-703. 